preventing the potentially dismal drawbacks of mechanical assistance.

\footnotetext{
References

1. Riahi M, Tomatis LA, Schlosser RJ, Bertolozzi E, Johnston DW. Cardiac compression due to closure of the median sternotomy in open-heart surgery. Chest. 1975; 67:113-4.

2. Freeman RK, Daily PO, Dembitsky WP, Adamson RM, Moreno-Cabral RJ. The treatment of low cardiac output syndrome following cardiopulmonary bypass using delayed sternal closure. Am Surg. 1997;63:882-4.
}

3. Josa M, Khuri S, Braunwald N, Vancisin MF, Spencer MP, Evans DA, et al. Delayed sternal closure: an improved method of dealing with complications after cardiopulmonary bypass. J Thorac Cardiovasc Surg. 1986;91: 598-603.

4. Anderson CA, Filsoufi F, Aklog L, Farivar RS, Byrne JG, Adams DH. Liberal use of delayed sternal closure for postcardiotomy hemodynamic instability. Ann Thorac Surg. 2002;73:1484-8.

5. Fleck T, Kickinger B, Moidl R, Waldenberger F, Wolner E, Grabenwoger M, et al. Management of open chest and delayed sternal closure with the vacuum assisted closure system: preliminary experience. Interact CardioVasc Thorac Surg. 2008; 7:801-4.

\title{
Papillary muscle-to-anterior annulus stitches: Another technique to prevent systolic anterior motion after mitral valve repair
}

\author{
Samer Kassem, MD, ${ }^{\mathrm{a}}$ and Hicham Jamil, MD, ${ }^{\mathrm{b}}$ Milan, Italy, and Damascus, Syria
}

Mitral valve reconstruction is the procedure of choice for mitral regurgitation, with excellent early and late results. ${ }^{1}$ Systolic anterior motion (SAM) may occur after mitral valve reconstruction as a result of various anatomic factors, such as degenerative mitral insufficiency with excessive leaflet tissue, nondilated left ventricular cavity, narrow mitroaortic angle, and anterior displaced mitral coaptation line. ${ }^{2,3}$ SAM, and consequent left ventricular outflow tract obstruction, occurs in more than $16 \%$ of patients after mitral valve repair. $^{2,3}$ In this report, we describe a new method to prevent the occurrence of SAM after mitroplasty. Two artificial chords are subsequently implanted in the posterior and anterior papillary muscles, then anchored to the midanterior mitral annulus to keep the anterior leaflet away from the septum during late diastole, to prevent its displacement into the left ventricle outflow tract during systole.

\footnotetext{
From the Department of Cardiovascular Surgery, ${ }^{a}$ Centro Cardiologico Monzino I.R.C.C.S, Milan, Italy; and the Department of Cardiovascular Surgery, ${ }^{\mathrm{b}}$ Damascus University Cardiovascular Hospital, Damascus, Syria.

Disclosures: Authors have nothing to disclose with regard to commercial support.

Received for publication Feb 7, 2011; revisions received March 17, 2011; accepted for publication March 28, 2011; available ahead of print May 2, 2011.

Address for reprints: Samer Kassem, MD, Centro Cardiologico Monzino, Via Parea 4, 20138 Milan, Italy (E-mail: skassem@ccfm.it).

J Thorac Cardiovasc Surg 2011;142:1278-81

0022-5223/\$36.00

Copyright (c) 2011 by The American Association for Thoracic Surgery doi:10.1016/j.jtcvs.2011.03.025
}

\section{SURGICAL TECHNIQUE}

The inspection of the mitral valve is carried out as usual. The leaflets are accurately analyzed, and the papillary muscles are inspected to identify the posterior head of each papillary muscle. A double-armed 4-0 polytetrafluoroethylene (Gore-Tex; W. L. Gore \& Associates, Flagstaff, Ariz) suture supported by a felt pledget is passed twice through the tip of the posterior head of the posterior papillary muscle with a forehand technique and is fixed with a loose knots to avoid necrosis (Figure 1, A). The ventricular surface of the anterior leaflet is inspected with two nerve hooks to explore the attachment of 1 secondary chord, which arises from the posterior papillary muscle (preferably the most distant from the leaflet's board, and toward the mitral anteroposterior axis) (Figure 1, A). The height of the selected chord is used as a guide for determining the length of the first part of the new chord. A metal clip is placed across the 2 arms of the new chord at the level of the anchor of the stretched native chord selected (Figure 1,A). The trace of the attachment of the selected chord on the atrial surface of the anterior leaflet is determined by insertion of a thin insulin needle as a marker beside the attachment's site. Thereafter, the anterior leaflet is once again pulled down into the ventricular cavity, leaving the insulin needle in place (Figure 1, $B$ ). On the atrial surface of the anterior leaflet, the distance between the marker (the insulin needle) and the anterior annulus determines the length of the second part of the new chord, which will be anchored to the anterior annulus with no excessive tension during the presystolic phase. Multiple 


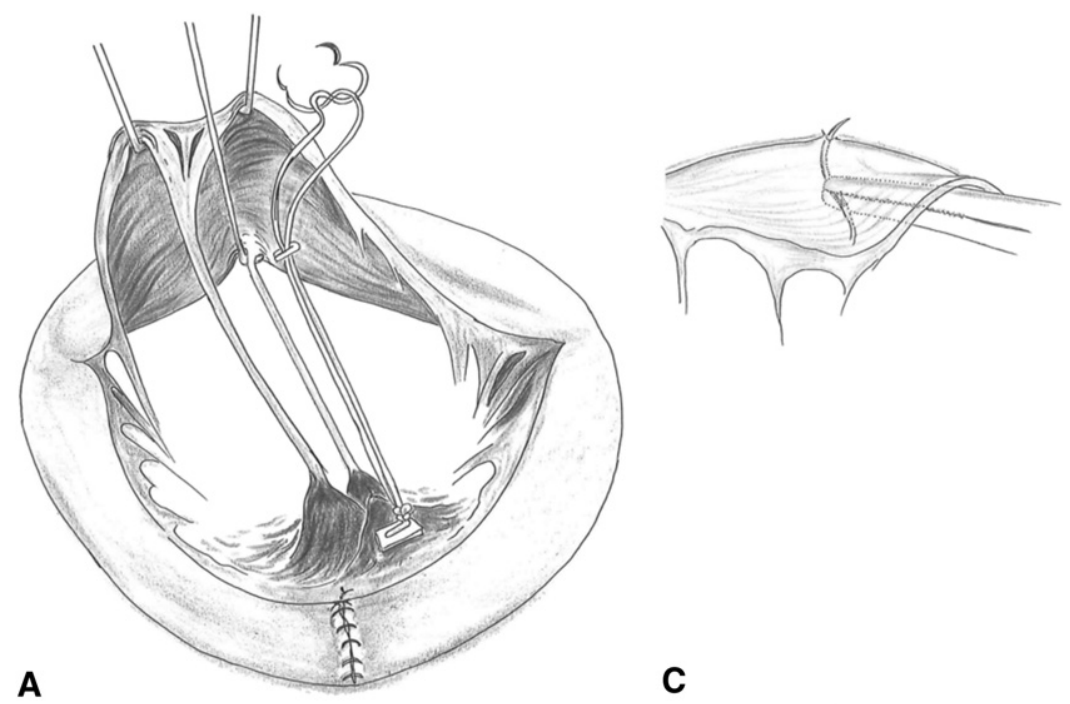

A

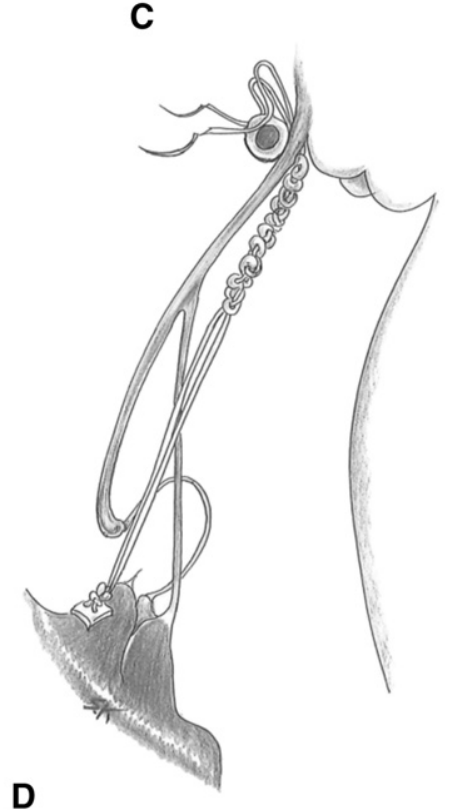

FIGURE 1. A, A double-armed 4-0 polytetrafluoroethylene (Gore-Tex; W. L. Gore \& Associates, Flagstaff, Ariz) suture is passed twice through the tip of the posterior head of the posterior papillary muscle with a forehand technique. The new chord thus arises from the papillary side that faces the posterior ventricular wall. The surgeon's assistant uses a nerve hook to stretch the second chord selected. The length of the selected chord is used as a guide to determine the first part of the new chord. A metal clip is engaged across the 2 arms at the level of the attachment of the stretched native chord. B, Cross-profile illustration shows a thin insulin needle inserted from the ventricular to the atrial side through the anterior leaflet in the site of native chordal attachment. The distance from the marker to the anterior annulus determines the length of the second part of the new chord. Multiple knots have been tied against the metal clip. The whole length of the knots should correspond to the distance between the marker and midanterior mitral annulus, which is equal to the distance between the chordal attachment and the anterior annulus. C, The 2 arms of the suture are then passed through at about the midanterior mitral leaflet from the ventricular to the atrial surface side by means of a backhand technique, taking care not to injure the aortic valve. The surgeon thus cannot see the point of entry. D, Cross-profile Illustration represents the anterior ring in its definitive position. The marker has been removed. The needles of the atrial side of the Gore-Tex sutures are passed through the anterior prosthetic sheath.

knots are then tied against the metal clip until the whole length of the knots corresponds to the distance between the marker and midanterior mitral annulus (Figure 1,B). Subsequently, the clip is removed. Thereafter the anterior leaflet is pulled up to maximum with a nerve hook, and the insulin needle is gently removed from the anterior leaflet. The 2 arms of the suture are then passed through approximately the middle of the anterior mitral leaflet from 

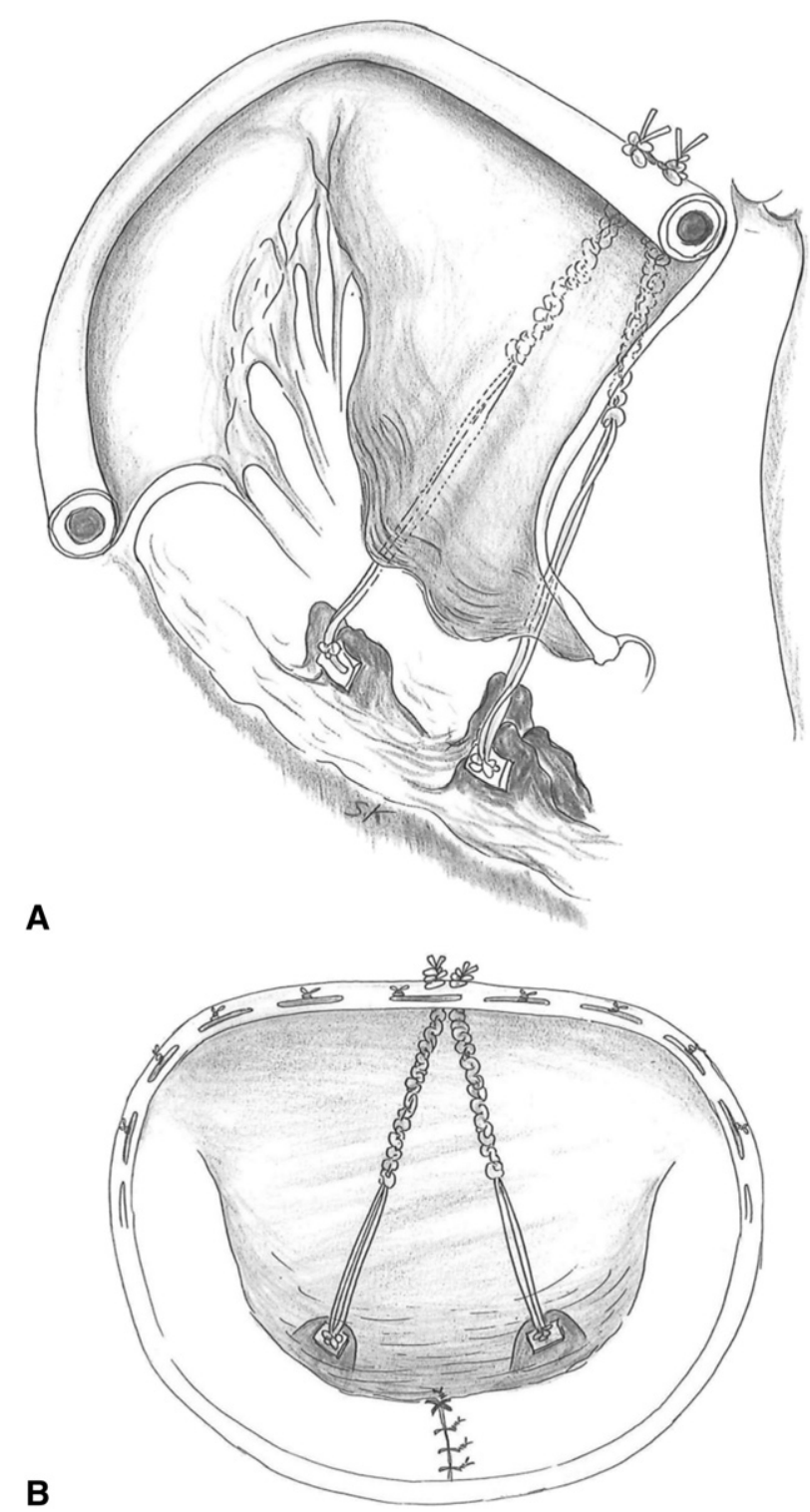

FIGURE 2. A, Cross-profile illustration shows the second papillary muscle-to-anterior annulus stitch, which arises from the posterior head of the anterior papillary muscle. The 2 new chords are tightly tied onto the prosthetic sheath. B, Illustration of the final position of the 2 papillary muscle-to-anterior annulus stitches as they would be seen by the surgeon if the anterior leaflet were transparent.

the ventricular to the atrial surface side by means of a backhand technique (Figure 1,C), and the suture is left untied. The procedure is repeated step by step to implant the second papillary muscle-anterior annulus chord, which arises from the posterior head of the anterior papillary muscle and is anchored to about the middle of the anterior mitral annulus. Subsequently, the surgeon continues the mitral repair, choosing the appropriate strategies for the lesions of the valve identified during the valve analysis. In our 4 selected cases, the posterior leaflet repair was performed with a traditional triangular resection (Figure 1, A). Finally, an annuloplasty Physio ring (Physio-Control, Inc, Redmond, Wash) is sized and added to complete the repair, maintaining free the untied Gore-Tex sutures outside the ring. When the ring is in its final position, the Gore-Tex sutures are passed through the anterior prosthetic sheath (Figure 1,C) and tightly knotted (Figure 2, A). After fluid testing to confirm the valve's competence (Figure 2, $B$ ), the atrium is once again closed.

\section{CLINICAL EXPERIENCE}

We have applied the papillary muscle-to-anterior annulus technique in the cases of 4 selected patients with severe degenerative mitral regurgitation as a result of $\mathrm{P} 2$ prolapse with redundant anterior leaflet and other factors predisposing them toward development of SAM. Intraoperative transesophageal echocardiography and early follow-up transthoracic echocardiography show the absence of SAM and no evidence of mitral valve stenosis (Figure 3, $C$ and $D$ ). None of the patients demonstrated atrial fibrillation, and oral anticoagulants with a target international normalized ratio of 2.5 were therefore used for just 3 months after mitral valve repair, in accordance with the European Society of Cardiology guidelines.

\section{DISCUSSION}

SAM may occur after mitral valve repair in $14 \%$ of patients with redundant and myxomatous anterior leaflet and nearly normal left ventricle size. ${ }^{4}$ The displacement of papillary muscles frontward or toward each other may increase chordal slack and laxity of the anterior leaflet (Figure 3, A). The myxomatous distal edge of the anterior leaflet suffers from laxity and chordal slack, even if there is no mitral insufficiency from elongated chordae tendineae (Figure 3, B). In addition, the lax tip of the anterior leaflet may move paradoxically under the influence of several forces. We therefore believe that to prevent SAM the surgery should aim not only at reducing the height of the posterior leaflet but also at disciplining the movement of the anterior leaflet. The anterior mitral leaflet forms most of the posterior wall of the left ventricular outflow tract. The aim of this technique is to create a barrier at the same level of the posterior wall of the left ventricular outflow tract to support the tip of the anterior leaflet and to prevent its dropping into the outflow tract during the early systolic phase (Figure 3,D), preserving its physiologic motion without compromising the flow across the valve or increasing the 

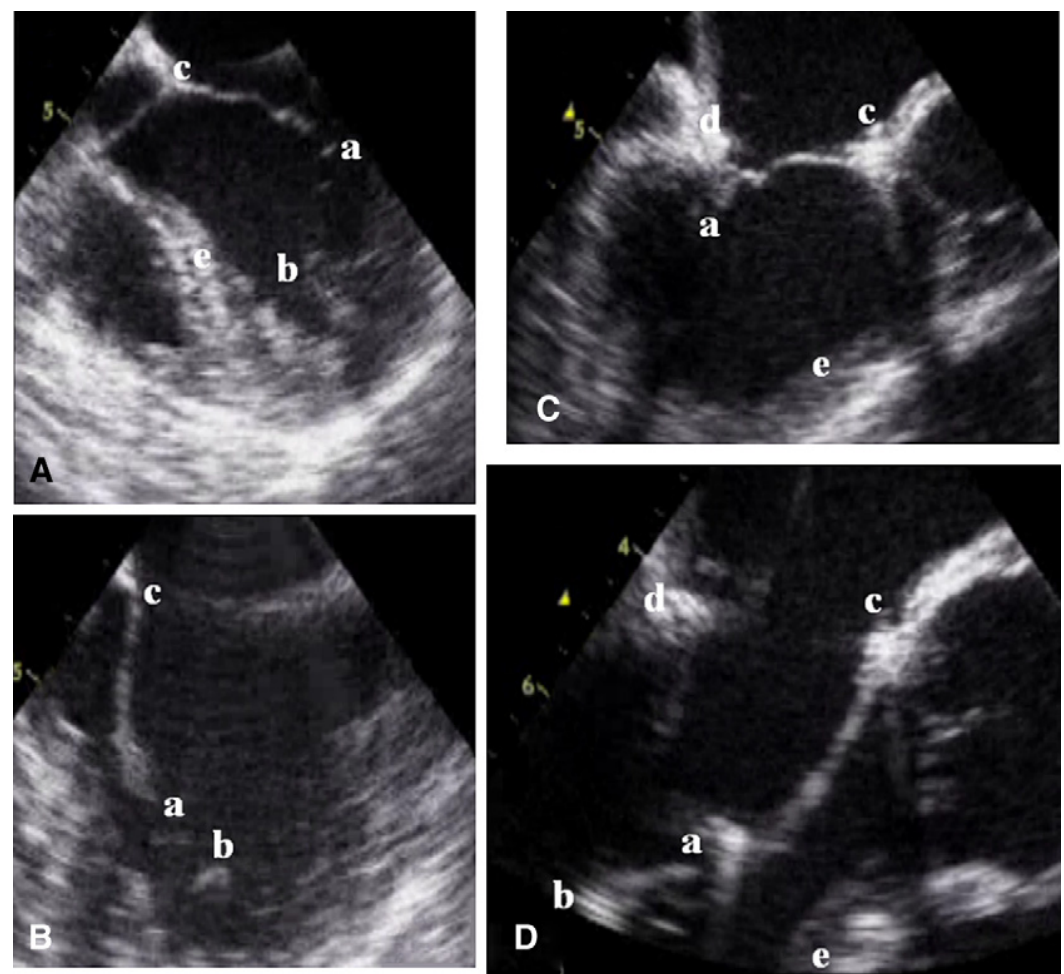

FIGURE 3. Transesophageal longitudinal echocardiographic views show edge of anterior leaflet (a), papillary muscle $(b)$, anterior mitral annulus $(c)$, posterior mitral annulus $(d)$, and ventricular septum $(e)$. A, Before mitral valve repair during systole. Anterior leaflet is long and redundant, with anterior displacement of the papillary muscle. B, Before mitral valve repair during diastole. C, After mitral valve repair during systole. The annuloplasty ring seems to be downsized, which might be a factor in development of systolic anterior motion. D, After mitral valve repair during diastole. Papillary muscle-to-anterior annulus stitches avoid the dropping of the tip of the anterior leaflet into the left ventricular outflow tract.

stress on the leaflets or the chordae tendineae. As a nonresection strategy, the use of this technique can avoid future effects of consolidation and cicatrization on the anterior leaflet that follow the required excisions in resection strategies.

We propose the papillary muscle-to-anterior annulus technique described here as an adjunct to mitral valve repairs to decrease the risk of postoperative SAM in patients with factors predisposing them toward this phenomenon. Nevertheless, more cases will be required to demonstrate the effectiveness of this technique.

\section{References}

1. Cohn LH, Couper GS, Aranki SF, Rizzo RJ, Kinchla NM, Collins JJ Jr. Long-term results of mitral reconstruction for regurgitation of the myxomatous mitral valve. J Thorac Cardiovasc Surg. 1994;107:143-51.

2. Jebara VA, Mihaileanu S, Acar C, Brizard C, Grare P, Latremouille C, et al. Left ventricular outflow tract obstruction after mitral valve repair. Results of the sliding leaflet technique. Circulation. 1993;88(5 Pt 2):II30-4.

3. Lee KS, Stewart WJ, Lever HM, Underwood PL, Cosgrove DM. Mechanism of outflow tract obstruction causing failed mitral valve repair. Anterior displacement of leaflet coaptation. Circulation. 1993;88(5 Pt 2):II24-9.

4. Mihaileanu S, Marino JP, Chauvaud S, Perier P, Forman J, Vissoat J, et al Left ventricular outflow obstruction after mitral valve repair (Carpentier's technique). Proposed mechanisms of disease. Circulation. 1988;78(3 Pt 2): I78-84. 